charged from hospital but readmitted 24 hours later with relapse. The rash was more severe, exfoliative, and superficially pustular, and her fever became undulant. Investigation showed a mild anaemia (haemoglobin $114 \mathrm{~g} / \mathrm{l}$ ), a very high leucocyte count $\left(22 \cdot 6 \times 10^{\circ}, 52 \%\right.$ neutrophils $)$, and abnormal liver function values ( $\gamma$-glutamyltransferase $417 \mathrm{IU} / \mathrm{l}$, aspartate transaminase $182 \mathrm{IU} / \mathrm{l}$, and alkaline phosphatase $560 \mathrm{IU} / 1$ hepatic isoenzyme). During her illness the antistreptococcal DNAase $B$ became positive, suggesting a recent streptococcal infection. The skin improved but liver function deteriorated; she went into hepatic coma and was transferred to King's College Hospital, but despite hepatic transplantation she died.

These cases followed a similar clinical pattern. In both continuous treatment with minocycline was followed after 32 days (case 1) and 29 days (case 2) by a severe exfoliative rash that became pustular with an inflammatory element showing features of both toxic epidermal necrolysis and erythema multiforme. The rash improved after 10 days (case 1) and 14 days (case 2). The liver function tests were abnormal at 42 days (case 1) and 37 days (case 2). In both they deteriorated but were showing evidence of improvement, in case 1 at 60 days. A curious feature was the positive antistreptococcal DNAase B, the titre of which rose during the early part of the illness in both cases. This test is much more specific for a streptococcal infection than the antistreptolysin $\mathrm{O}$ titre and appears to reflect true recent infection. The role of the streptococcal infection is not clear; it appears to have immediately preceded the illness and may have played a part as a cofactor. It was not solely responsible for the illness as neither a skin eruption of that type nor hepatic failure is a recognised feature of streptococcal infections. The rash was unusual, with features of erythema multiforme and toxic epidermal necrolysis most likely to be seen in a drug eruption. The liver failure might also have been drug induced and appeared to have been so in the absence of positive hepatitis titres. Other infective causes in case 2 were extensively sought and not found.

There is one previous case report of hepatitis associated with minocycline in a patient with an aspiration pneumonia.' In that case the pneumonia, from which cultures grew Staphylococcus aureus and Streptococcus salivarius, had been treated with minocycline and ampicillin. The Committee on Safety of Medicines has received nine reports of hepatic dysfunction associated with minocycline and eight reports of rashes, one of which was described as exfoliative dermatitis.

We believe that there is a case for caution in the use of minocycline for minor skin complaints and would be interested to hear of any other patients with a similar history to our two patients.

1 Burette A, Finet C, Priogine T, De Roy G, Deltenre M. Acute hepatic injury associated with minocycline. Arch Intern Med 1984;144:1491-2.

\section{Idiosyncratic dapsone induced manic depression}

Drs ANdrew J Carmichael and C J Paul (Skin Hospital, Birmingham B15 1PR) write: We have recently seen a case of manic depressive psychosis induced by dapsone and unrelated to leprosy.

A 37 year old white woman had suffered recurrent attacks of erythema multiforme for seven years, localised to the skin of the arms. Attacks occurred most months, with the lesions spontaneously settling over two weeks. Investigations for an underlying cause, including lupus erythematosus, gave negative results, and she was otherwise well. A more extensive episode of erythema multiforme affecting the face prompted us to start dapsone $100 \mathrm{mg} /$ day in view of our recent experience of response to this treatment.'
Twenty four hours after starting the drug the patient had a two day episode of hypomania, with flight of ideas, pressure of speech, marked hyperactivity, and lack of need for sleep. After three more days she entered a depressive state, becoming withdrawn, low in affect, and tearful, with no change in her life circumstances. She gave no personal or family history of psychiatric problems and was taking no other medication. Her haemoglobin concentration was normal and methaemoglobin was undetected. Dapsone was stopped after 10 days' treatment and within a fortnight her mood had returned to normal. The erythema multiforme cleared after a week's treatment with dapsone but relapsed three weeks after discontinuing treatment.

Dapsone associated "psychosis" has been the subject of controversy.' The debate has been muddied both by imprecise classification of the psychosis and by all but one ${ }^{2}$ recorded case occurring against a background of leprosy, which may itself be associated with psychotic symptoms. ${ }^{3}$ Some have suggested that "dapsone psychosis" is dose related, ${ }^{3}$ occurs only in those with a background of psychiatric problems, ${ }^{+}$and is therefore partly predictable. In view of the strong temporal relation of our patient's symptoms to dapsone treatment and her recovery after its withdrawal we believe that her manic depressive psychosis was a side effect of dapsone. Rechallenge was not thought to be ethical given the severity of the psychiatric symptoms. This manic-depressive reaction, like the severe agitation in the non-lepromatous patient described by Fine et $a l,{ }^{2}$ appeared after a small dose of dapsone with no predisposing factors and was therefore unpredictable.

1 Durha P, Paul CJ. Continuous erythema multiforme clearing on dapsone. Br f Dermatol 1988;118:731.

2 Fine JD, Katz SI, Donahue MJ, Hendricks AA. Psychiatric reaction to dapsone and sulfapyridine. $\mathcal{J}$ Am Acad Dermatol reaction to

3 Jopling WH. Antileprosy drugs. Br Med F 1971;iv:366.

4 Molesworth BD, Narayanswami PS. Toxic effects of diaminodiphenylsulphone. Lancet 1952; ; :562-3.

\section{Breathlessness in patients with prostatic carcinoma treated with cyproterone acetate}

Mr N A Green (Norfolk and Norwich Hospital, Norwich) and DR B D W HARRISON (West Norwich Hospital, Norwich NR2 3TU) write: Breathlessness in men with prostatic carcinoma is not uncommon and may be due to coexisting heart or lung disease, pulmonary metastases, fluid retention associated with oestrogen therapy, pulmonary emboli, or anaemia. We describe three patients who complained of breathlessness within a month of starting treatment with cyproterone acetate, none of whom had any of these causes of breathlessness.

The three men with carcinoma of the prostate were all smokers and each had evidence of mild or moderate airways obstruction on pulmonary func-

Respiratory and blood gas values in three patients taking cyproterone acetate for prostatic carcinoma

\begin{tabular}{|c|c|c|c|c|c|c|c|c|c|}
\hline $\begin{array}{l}\text { Case } \\
\text { No }\end{array}$ & $\begin{array}{c}\text { Age } \\
\text { (years) }\end{array}$ & $\begin{array}{l}\text { Cyproterone } \\
\text { acetate treatment }\end{array}$ & $\begin{array}{l}\mathrm{FEV}_{1}{ }^{*} \\
(\mathrm{I})\end{array}$ & $\begin{array}{l}\mathrm{FVC}^{\star} \\
(\mathrm{I})\end{array}$ & $\begin{array}{c}\mathrm{PaO}_{2} \\
(\mathrm{kPa}) \\
(11-13) \dagger\end{array}$ & $\begin{array}{c}\mathrm{PaCO}_{2} \\
(\mathrm{kPa}) \\
(4 \cdot 8-6 \cdot 3) \dagger\end{array}$ & $\begin{array}{c}\mathrm{pH} \\
(7 \cdot 35-7 \cdot 45) \dagger\end{array}$ & $\begin{array}{l}\text { Bicarbonate } \\
(\mathrm{mmol} / \mathrm{l}) \\
(22-32) \dagger\end{array}$ & Date \\
\hline \multirow[t]{2}{*}{1} & \multirow[t]{2}{*}{70} & $\begin{array}{l}100 \mathrm{mg} \text { thrice daily } \\
\text { Started Dec } 86\end{array}$ & $\begin{array}{c}3 \cdot 28 \\
(2 \cdot 59)\end{array}$ & $\begin{array}{c}4 \cdot 84 \\
(3 \cdot 78)\end{array}$ & 13.6 & $3 \cdot 2$ & $7 \cdot 428$ & $15 \cdot 9$ & $18 \mathrm{Mar} 87$ \\
\hline & & Stopped Jun 87 & & & $\begin{array}{l}13 \cdot 1 \\
10 \cdot 9\end{array}$ & $\begin{array}{l}3 \cdot 6 \\
4 \cdot 6\end{array}$ & $\begin{array}{l}7 \cdot 439 \\
7 \cdot 433\end{array}$ & $\begin{array}{l}17 \cdot 9 \\
22 \cdot 8\end{array}$ & $\begin{array}{l}9 \text { Jun } 87 \\
31 \text { Oct } 88\end{array}$ \\
\hline \multirow[t]{2}{*}{2} & \multirow[t]{2}{*}{67} & $\begin{array}{l}100 \mathrm{mg} \text { thrice daily } \\
\text { Started Nov } 86\end{array}$ & $\begin{array}{l}1.74 \\
(2 \cdot 46)\end{array}$ & $\begin{array}{c}3 \cdot 14 \\
(3 \cdot 49)\end{array}$ & $13 \cdot 6$ & $2 \cdot 7$ & $7 \cdot 449$ & $13 \cdot 7$ & 26 Oct 87 \\
\hline & & & & & $13 \cdot 7$ & $3 \cdot 8$ & $7 \cdot 437$ & $18 \cdot 9$ & 14 Nov 88 \\
\hline 3 & 70 & $\begin{array}{l}100 \mathrm{mg} \text { thrice daily } \\
\text { Started Jun } 88 \\
\text { Stopped Sep } 88\end{array}$ & $\begin{array}{c}2.51 \\
(3.04)\end{array}$ & $\begin{array}{c}4 \cdot 45 \\
(4.37)\end{array}$ & $12 \cdot 9$ & $3 \cdot 7$ & $7 \cdot 450$ & $19 \cdot 3$ & 3 Aug 88 \\
\hline
\end{tabular}

$\mathrm{FEV}_{1}=$ Forced expired volume in one second. $\mathrm{FVC}=$ Forced vital capacity. $\mathrm{PaO}_{2}=$ Arterial oxygen pressure. Paco $_{2}=$ Arterial carbon dioxide pressure.

${ }^{\star}$ Figures in parentheses are predicted normal values. $†$ Normal range.

tion tests (table), but none had previously complained of breathlessness. One man (case 3) also had pleural calcification after artificial pneumothoraces for pulmonary tuberculosis 40 years earlier. Each patient noticed and complained of breathlessness on exertion within a month of starting cyproterone acetate. Two were dyspnoeic while undressing. None had wheezed or experienced orthopnoea. Blood gas pressures and $\mathrm{pH}$ are also shown in the table. All showed a normal arterial oxygen pressure, a low carbon dioxide pressure, and a high normal $\mathrm{pH}$ with a low bicarbonate concentration, which indicated a chronic or compensated respiratory alkalosis. Repeat studies in two of the patients after three and 13 months, while they were still taking cyproterone acetate, showed the persistence of the chronic respiratory alkalosis. Two men stopped cyproterone (table) and noticed an improvement in breathlessness within a few days. Further studies in one man 16 months after he stopped treatment showed that his hyperventilation had ceased and his arterial carbon dioxide pressure and $\mathrm{pH}$ were both normal.

Progesterone and progestogens stimulate ventilation and increase the sensitivity of the respiratory centre to carbon dioxide.' One of the causes of breathlessness during pregnancy is hyperventilation caused by the increased progesterone secretion, and medroxyprogesterone has been used as a respiratory stimulant in patients with chronic ventilatory failure. ${ }^{3}$ Cyproterone acetate acts as an antiandrogen by blocking androgen receptors. It also has progestogenic activity, exerting a negative feedback effect on the hypothalamic receptors, thus diminishing gonadotrophin release. ${ }^{*}$

Our patients attributed their pulmonary symptoms to the cyproterone since all noticed breathlessness soon after treatment started. None had sufficient underlying lung disease or sufficiently abnormal pulmonary function to account for their dyspnoea. All had normal arterial oxygen pressures and evidence of a chronic or compensated respiratory alkalosis consistent with a chronic stimulus to hyperventilation. In one man the dyspnoea and acid base abnormality resolved after the cyproterone was stopped. In another, who declined further tests, breathlessness improved after cyproterone was stopped. In the absence of any other cause of breathlessness we postulate that it was due to the progestogenic effects of cyproterone acetate increasing ventilation in patients with a pre-existing mild to moderate degree of abnormal pulmonary function.

Weinberger SE, Weiss ST, Cohen WR, Weiss JW, Johnson TS Pregnancy and the lung. Am Rev Respir Dis 1980;121:559-81. 2 Lyons HA, Antonio R. The sensitivity of the respiratory centre in pregnancy and after the administration of progesterone. Trans Assoc Am Physicians 1959;72:173-80.

3 Sutton FD, Zwillich CW, Creagh CE, Pierson DJ, Weil JV. Progesterone for outpatient treatment of Pickwickian syndrome. Ann Intern Med 1975;83:476-9.

4 Eaton AC, McGuire N. Cyproterone acetate in treatment of post orchidectomy hot flushes. Double blind crossover trial. Lance 1983;ii:1336-7. 